\title{
Article \\ Highly Enhanced Enzymatic Activity of Mn-Induced Carbon Dots and Their Application as Colorimetric Sensor Probes
}

\author{
Ahyun Lee, Wooseok Kang and Jin-sil Choi * \\ Department of Chemical and Biological Engineering, Hanbat National University, Daejeon 34158, Korea; \\ leeah3238@gmail.com (A.L.); gne01041@gmail.com (W.K.) \\ * Correspondence: jinsil.choi@hanbat.ac.kr
}

Citation: Lee, A.; Kang, W.; Choi, J.-s. Highly Enhanced Enzymatic Activity of Mn-Induced Carbon Dots and Their Application as Colorimetric Sensor Probes. Nanomaterials 2021, 11, 3046. https://doi.org/10.3390/ nano11113046

Academic Editors: Jose M. Palomo and Moonis Ali Khan

Received: 30 September 2021 Accepted: 9 November 2021 Published: 12 November 2021

Publisher's Note: MDPI stays neutral with regard to jurisdictional claims in published maps and institutional affiliations.

\begin{abstract}
Nanomaterial-based enzyme mimetics (nanozymes) have attracted significant interest because of their lower cost and higher stability compared to natural enzymes. In this study, we focused on improving the enzymatic properties of metal induced N-doped carbon dots (N-CDs), which are nanozymes of interest, and their applications for sensory systems. For this purpose, $\mathrm{Mn}$ (acetate) 2 was introduced during the synthetic step of $\mathrm{N}$-doped carbon dots, and its influence on the enzymatic properties of Mn-induced N-CDs (Mn:N-CDs) was investigated. Their chemical structure was analyzed through infrared spectroscopy and X-ray photoelectron spectrometry; the results suggest that $\mathrm{Mn}$ ions lead to the variation in the population of chemical bonding in $\mathrm{Mn}: \mathrm{N}-\mathrm{CDs}$, whereas these ions were not incorporated into N-CD frameworks. This structural change improved the enzymatic properties of Mn:N-CDs with respect to those of N-CDs when the color change of a 3,3',5,5'-tetramethylbenzidine $/ \mathrm{H}_{2} \mathrm{O}_{2}$ solution was examined in the presence of $\mathrm{Mn}$ : N-CDs and $\mathrm{N}-\mathrm{CD}$. Based on this enhanced enzymatic property, a simple colorimetric system with Mn:N-CDs was used for the detection of $\gamma$-aminobutyric acid, which is an indicator of brain-related disease. Therefore, we believe that Mn:N-CDs will be an excellent enzymatic probe for the colorimetric sensor system.
\end{abstract}

Keywords: carbon dots; Mn ions; nanozyme; enzymatic activity; GABA detection; colorimetric sensor

\section{Introduction}

In sensor systems, a chemical or physical transducer converts a chemical or biological signal into a recognizable signal (e.g., color or electrical signal). Natural enzymes are effective chemical transducers, and they are widely used in sensor systems [1,2]. For example, in the conventional enzyme-linked immunosorbent assay (ELISA), natural enzymes (e.g., horseradish peroxidase, HRP) catalyze different colorimetric reactions in the presence of substrates [3-5]. In addition, $\mathrm{HRP}$ accelerates $\mathrm{H}_{2} \mathrm{O}_{2}$-dependent one-electron oxidation, generating an electrical signal that allows for the sensitive detection of targets [6-9]. Regardless of their novel catalytic effectiveness, natural enzymes have limitations in industrial applications, such as low stability in harsh environmental conditions and relatively high costs of preparation, purification, and storage. Therefore, over the past few decades, researchers have made extensive efforts to develop replacements.

Nanomaterial-based enzyme mimetics (nanozymes) attract significant interest because of their low cost and high stability relative to those of natural enzymes, leading to their application in diverse fields including biosensing [10-17]. Among various nanozymes, carbon dots (CDs) are emerging materials owing to their unique properties [18-21]. Numerous researchers have investigated not only the enzymatic properties of CDs but also methods to improve these properties. For example, CDs that were doped with hetero ions such as $S$ or $P$ could easily catalyze $3,3^{\prime}, 5,5^{\prime}$-tetramethylbenzidine (TMB) to produce oxidized TMB in the presence of $\mathrm{H}_{2} \mathrm{O}_{2}$ [22,23]. The enzymatic properties of CDs are considerably improved through the formation of hybrids with other materials (e.g., $\mathrm{Au}, \mathrm{Pd}, \mathrm{Fe}_{3} \mathrm{O}_{4}$, 
$\mathrm{Mn}_{3} \mathrm{O}_{4}$, and $\mathrm{CeO}_{2}$ ) [24-27]. Metal ions (e.g., $\mathrm{Mn}$ and $\mathrm{Fe}$ ) with multiple oxidation states promote the enzymatic activity of CDs [28-31]. The simple addition of metal ions and chelate molecules to the reaction solution accelerates the enzymatic activity of CDs at a neutral $\mathrm{pH}$ [32]. Doping metal species into a $\mathrm{CD}$ framework can act as a catalase mimic and reduce oxidative-stress-related damage on CDs by decomposing $\mathrm{H}_{2} \mathrm{O}_{2}$ to $\mathrm{H}_{2} \mathrm{O}$ and $\mathrm{O}_{2}$ [28]. Metal ions can also influence the formation of $\mathrm{CDs}$ and induce variations in the chemical structure of CDs during their synthesis, leading to the enhancement of physicochemical properties [29]. However, the enzymatic properties of metal-induced CDs have rarely been examined.

In this study, the effect of Mn on the formation of Mn-induced N-doped CDs (Mn:N$\mathrm{CDs}$ ) and the resulting enzyme-like properties of $\mathrm{Mn}: \mathrm{N}-\mathrm{CDs}$ were investigated. $\mathrm{Mn}$ (acetate) ${ }_{2}$ was added during the synthesis of N-doped CDs ( $\mathrm{N}-\mathrm{CDs})$. However, $\mathrm{Mn}$ ions were not incorporated into the $\mathrm{CD}$ framework. The analysis of the chemical composition of $\mathrm{Mn}: \mathrm{N}-\mathrm{CDs}$ using X-ray photoelectron spectrometry (XPS) and infrared (IR) spectroscopy showed that $\mathrm{Mn}$ (acetate) ${ }_{2}$ leads to a change in the composition of the chemical bonding of Mn:N-CDs with respect to that of N-CDs synthesized without the addition of Mn(acetate) $)_{2}$. Mn:N-CDs show better peroxidase-like properties than $\mathrm{N}$-CDs. Based on these enhanced enzymatic properties, Mn:N-CDs can be used as colorimetric sensor probes to detect various disease factors. In this study, $\gamma$-aminobutyric acid (GABA), which is known as a metabolite of the human microbiome and an indicator of various brain diseases, was successfully detected using a Mn:N-CD-based colorimetric sensor system.

\section{Materials and Methods}

\subsection{Reagents}

Citric acid (99.9\%), ethylenediamine ( $>98 \%), \mathrm{Mn}(\text { acetate })_{2}, \mathrm{H}_{2} \mathrm{O}_{2}, \mathrm{TMB}(97 \%)$, GABA ( $\geq 99 \%$ ), and a 3-(4,5-dimethylthiazol-2-yl)-2,5-diphenyltetrazolium bromide (MTT) assay kit were purchased from Sigma Aldrich (St. Louis, MO, USA) and used as received.

\subsection{Equipment}

The morphology and lattice distance of $\mathrm{Mn}: \mathrm{N}-\mathrm{CDs}$ were investigated via transmission electron microscopy (TEM; Tecnai G2 F30 S-Twin, FEI, Hillsboro, OR, USA) and the H-7650 system (Hitachi, Tokyo, Japan) installed at the Center for University-wide Research Facilities at Jeonbuk National University. X-ray diffraction (XRD) was performed using SmartLab (Rigaku, Tokyo, Japan). The chemical functional groups and composition of Mn:N-CDs were examined through Fourier-transform infrared (FT-IR) spectrometry (Nicolet 6700, ThermoFisher Scientific, Waltham, MA, USA) and XPS (K-Alpha+, ThermoFisher Scientific, Waltham, MA, USA), respectively. The amount of Mn in Mn:N-CDs was measured using inductively coupled plasma-mass spectrometry (ICP-MS; ELAN DRC II PerkinElmer, Waltham, MA, USA).

\subsection{Synthesis of $M n: N-C D s$}

$\mathrm{Mn}: \mathrm{N}-\mathrm{CDs}$ were prepared by employing a hydrothermal method that is a modified synthetic method reported in our previous work [22]. In a typical synthesis procedure, citric acid $(10 \mu \mathrm{mol})$, ethylenediamine $(5 \mu \mathrm{mol})$, and $\mathrm{Mn}(\text { acetate })_{2}(4.15 \mu \mathrm{mol})$ were dissolved in deionized (DI) water $(15 \mathrm{~mL})$. Then, the mixture was heated hydrothermally in a Teflonequipped stainless-steel autoclave at $200{ }^{\circ} \mathrm{C}$. After $1 \mathrm{~h}$, the mixture was cooled to room temperature, and the residue was purified using column chromatography (CombiFlash NextGen 100, Teledyne ISCO, Lincoln, NE, USA) to obtain brown Mn:N-CDs.

\subsection{Enzyme-Mimicking Activities of $M n: N-C D s$}

The peroxidase-like activity of Mn:N-CDs was measured using TMB as the substrate. Specifically, a $100 \mathrm{mM} \mathrm{H}_{2} \mathrm{O}_{2}$ solution, $10 \mathrm{mM} \mathrm{TMB}$ solution, and a Mn:N-CD suspension $\left(500 \mu \mathrm{g} \cdot \mathrm{mL}^{-1}\right)$ were added to a citric acid buffer $(150 \mathrm{mM}$, at $\mathrm{pH} 2)$, and the mixture was shaken thoroughly to ensure homogeneous mixing. The absorption of the sample at $652 \mathrm{~nm}$ 
was measured immediately using a multimode plate reader (SpectraMax M2e, Molecular Devices, LLC, San Jose, CA, USA). The relationship between the initial velocity, $V$, and the substrate concentration, $[S]$, is given by the Michaelis-Menten equation as follows:

$$
V=\frac{[S] V_{\max }}{[S]+K_{m}} .
$$

Here, $V_{\max }$ is the maximum initial velocity of the enzymatic reaction, and $K_{m}$ is the Michaelis constant, which represents the concentration of the substrate at half the maximum velocity. The linear regression curve of the relationship between $1 / V$ and $1 /[S]$, viz. the Lineweaver-Burk plot, can be obtained by inverting the Michaelis-Menten equation to the following form:

$$
\frac{1}{V}=\frac{K_{m}}{V_{\max }} \frac{1}{[S]}+\frac{1}{V_{\max }} .
$$

In the plot of $1 / V$ vs. $1 /[S]$, the ordinate and abscissa intercepts represent the inverse of $V_{\max }$ and $-1 / K_{m}$, respectively. $K_{m}$ and $V_{\max }$ were estimated from these intercepts.

\subsection{Detection of GABA Using the Colorimetric Sensor System}

GABA was detected using TMB as the substrate, GABA (25-400 nM), and Mn:N-CD $\left(0.5 \mathrm{mg} \cdot \mathrm{mL}^{-1}\right)$, all of which were mixed in a citric acid buffer $(150 \mathrm{mM}, \mathrm{pH} 2)$ and incubated for $15 \mathrm{~min}$. Then, $\mathrm{H}_{2} \mathrm{O}_{2}(100 \mathrm{mM})$ and TMB $(10 \mathrm{mM})$ were added to the reaction solution, and the solution was vortexed for homogeneous mixing. Immediately after mixing, the absorption of the sample at $652 \mathrm{~nm}$ was measured at intervals of $1 \mathrm{~min}$ for $10 \mathrm{~min}$ using a multimode plate reader (SpectraMax M2e, Molecular Devices, LLC, San Jose, CA, USA).

\section{Results}

Mn:N-CDs were obtained using the previously reported hydrothermal method [22]. Citric acid and ethylenediamine were the sources of carbon, and their reaction molar ratio was 1:0.5. $\mathrm{Mn}$ (acetate) $)_{2}$ was also added, and the reaction ratio of $\mathrm{Mn}$ (acetate) $)_{2}$ to citric acid was 1:0.4 (Figure 1a). The TEM images shown in Figure 1a reveal that Mn:N-CDs possessed a round shape with an average diameter of $6.7 \mathrm{~nm}$ (Figure 1b). The high-resolution (HR) TEM image confirmed that Mn:N-CDs had a crystalline structure with a lattice distance of $0.24 \mathrm{~nm}$, which matched the (100) plane of graphite (Figure 1c) [33,34]. In the XRD spectrum, Mn:N-CDs showed a broad peak at $19.14^{\circ}$ corresponding to the (002) plane of graphite (JCPDS card no. 26-1076) (Supplementary Materials Figure S1) [35,36].

The chemical structure of Mn:N-CDs was further investigated using FT-IR and XPS. Comparing the FT-IR spectra of Mn:N-CDs and N-CDs indicated no differences in the composition of the chemical functional groups (Supplementary Materials Figure S2). However, the spectrum of Mn:N-CDs showed a significant increase in the intensity of the peak at $1560 \mathrm{~cm}^{-1}$, which corresponds to the stretching of the $\mathrm{N}-\mathrm{O}$ bond [37-39]. Figure 2 shows the chemical composition of Mn:N-CDs obtained via XPS. In the XPS survey profile of $\mathrm{Mn}: \mathrm{N}-\mathrm{CDs}$ (Figure 2a), peaks originating from $\mathrm{C}_{1 \mathrm{~s}}, \mathrm{~N}_{1 \mathrm{~s}}$, and $\mathrm{O}_{1 \mathrm{~s}}$ can be clearly observed, whereas the $\mathrm{Mn}_{2 \mathrm{p}}$ peak is absent. The ICP-MS analysis (Supplementary Materials Table S1) shows that the amount of $\mathrm{Mn}$ ions in $\mathrm{Mn}: \mathrm{N}-\mathrm{CDs}$ is negligible. Thus, Mn ions might not be doped or chelated in Mn:N-CDs. Based on the area of each peak in the XPS spectra (Supplementary Materials Figure S3a), the atomic compositions of Mn:N-CDs and N-CDs are found to be similar. However, differences exist in the distributions of functional groups between Mn:N-CDs and N-CDs. The chemical bonding of each atomic component was investigated in detail through a spectral peak fitting of the high-resolution $\mathrm{C}_{1 \mathrm{~s}}, \mathrm{~N}_{1 \mathrm{~s}}$, and $\mathrm{O}_{1 \mathrm{~s}}$ spectra on the basis of the reported values of chemical bonds, as shown in Figure $2 b-\mathrm{d}$ and Figure S3b. In the $\mathrm{C}_{1 \mathrm{~s}}$ spectra (Figure $2 \mathrm{~b}$ ), a strong peak appears at $284 \mathrm{eV}$, corresponding to the $\mathrm{C}-\mathrm{C} / \mathrm{C}=\mathrm{C}$ bond of the carbogenic domain, along with the peaks for $\mathrm{C}-\mathrm{O}(285.5 \mathrm{eV})$ and $\mathrm{C}=\mathrm{O}\left(288.0 \mathrm{eV}\right.$ ). In the $\mathrm{N}_{1 \mathrm{~s}}$ spectra (Figure 2c), Mn:N-CDs show a strong $\mathrm{N}_{\text {pyrrole }}$ peak $(399.5 \mathrm{eV})$, which is found at the edge sites of the carbogenic domain, and weak $\mathrm{N}_{\text {graphite }}$ 
peak $(401 \mathrm{eV})$, which is located in the $\mathrm{sp}^{2}$-carbon domain. Furthermore, the $\mathrm{O}_{1 \mathrm{~s}}$ spectrum is composed of two peaks corresponding to $\mathrm{C}-\mathrm{O}$ and $\mathrm{C}=\mathrm{O}$ bonds $(532.6$ and $531.1 \mathrm{eV}$, respectively) (Figure 2d). Integrating the area of each fitted peak reveals that compared with N-CDs, Mn:N-CDs possess a higher proportion of $\mathrm{C}=\mathrm{O}$ and $\mathrm{N}_{\text {pyroline, }}$, which exist at the edge of carbogenic domains, and a lower proportion of $\mathrm{C}-\mathrm{C} / \mathrm{C}=\mathrm{C}$ and $\mathrm{N}_{\text {graphene }}$ in carbogenic domains (Supplementary Materials Figure S3b). The addition of $\mathrm{Mn}\left(\right.$ acetate) ${ }_{2}$ appears to perturb the formation of the carbogenic domain, thereby increasing the amounts of functional groups on the edge of $\mathrm{sp}^{2}$ carbogenic domains.

a
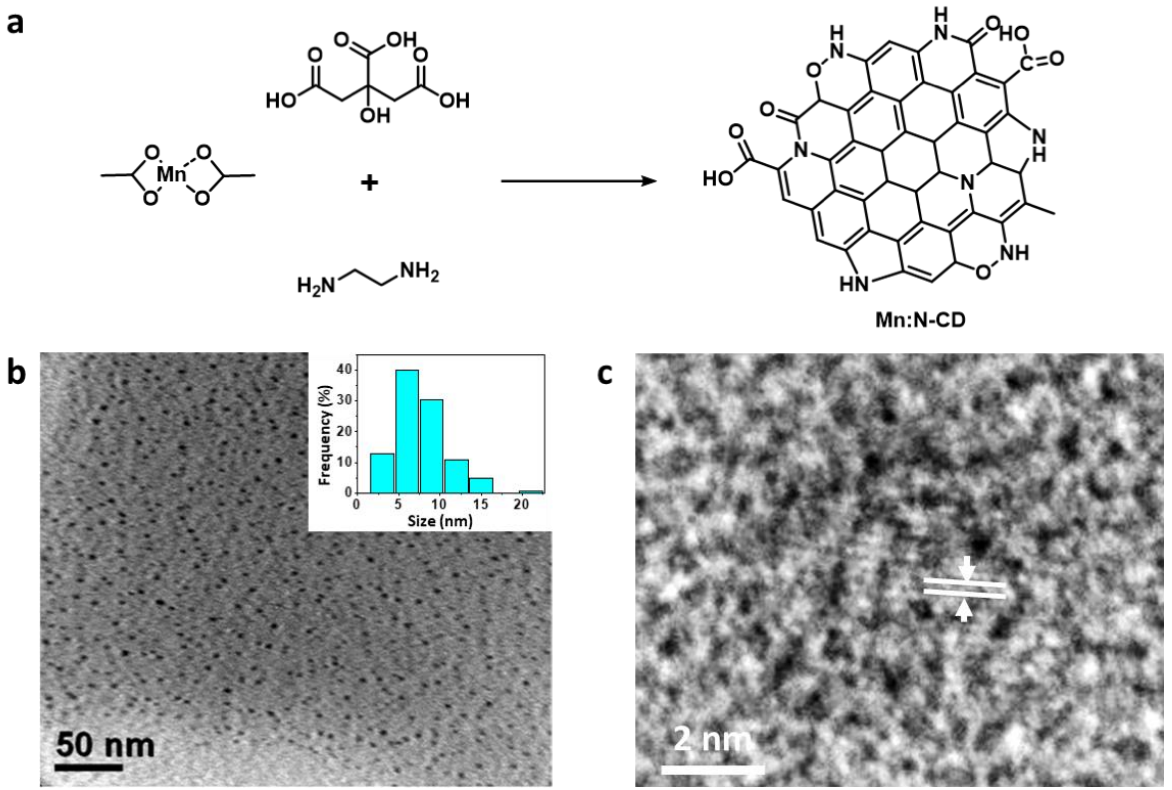

Figure 1. (a) Schematic of the synthesis of Mn-induced N-doped carbon dots (Mn:N-CDs). (b) Lowresolution and (c) high-resolution transmission electron microscopy images of the Mn:N-CDs. Inset in (b) particle size distribution.
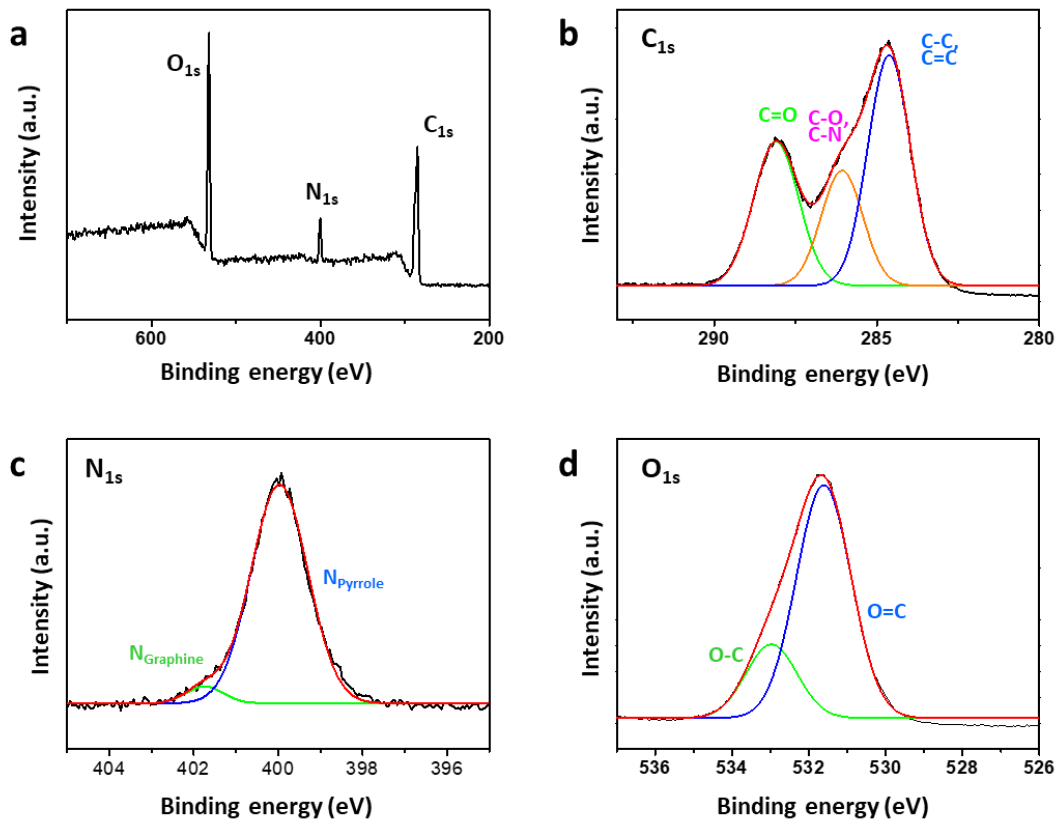

Figure 2. (a) $\mathrm{X}$-ray photoelectron spectrometry survey scan profile and high-resolution (b) $\mathrm{C}_{1 \mathrm{~s}}$, (c) $\mathrm{N}_{1 \mathrm{~s}}$, and (d) $\mathrm{O}_{1 \mathrm{~s}}$ spectra of Mn:N-CDs. 
Next, the enzyme-like activity of Mn:N-CDs is explored. In our previous study [22], $\mathrm{N}$-CDs were confirmed to show peroxidase-mimicking activity; thus, the peroxidase-like activities of Mn:N-CDs are examined here by monitoring the change in the color of a mixed solution of TMB $(10 \mathrm{mM})$ and $\mathrm{H}_{2} \mathrm{O}_{2}(100 \mathrm{mM})$ at $\mathrm{pH} 2$ (Figure 3a). With the addition of $\mathrm{Mn}: \mathrm{N}-\mathrm{CDs}$, the color of the TMB solution changes from pale yellow to blue owing to the oxidation of TMB (Figure 3b), whereas N-CDs cause a negligible change in the color of the TMB solution under the same experimental conditions. The time-dependent absorption at $652 \mathrm{~nm}$ is monitored in a steady-state kinetics study, and the result suggest that Mn:N-CDs exhibit significantly higher absorption at $652 \mathrm{~nm}$ than N-CDs, thereby presenting superior peroxidase-like activity (Figure 3c). The enzymatic activity of Mn:N-CDs is estimated by calculating the $\mathrm{V}_{\max }$ and $\mathrm{K}_{\mathrm{m}}$ values of the reaction in the presence of Mn:N-CDs using the Lineweaver-Burk equation (Figure $3 \mathrm{~d}$ and Supplementary Materials Figure S4). Mn:N-CDs show a slightly lower $\mathrm{V}_{\max }$ value $\left(0.11 \mu \mathrm{M} \cdot \mathrm{s}^{-1}\right)$ than $\mathrm{N}-\mathrm{CDs}\left(0.14 \mu \mathrm{M} \cdot \mathrm{s}^{-1}\right)$ (Figure 3d). This may be because compared with N-CDs, Mn:N-CDs have a lower amount of graphitic N atoms, which help generate radical oxygen species [40] (Supplementary Materials Figure S3b). However, there is a large difference between the values of $K_{m}$, which represents the affinity between a substrate and enzyme (Mn:N-CDs: $0.14 \mathrm{mM}$; N-CDs: $3.88 \times 10^{3} \mathrm{mM}$ ) (Figure 3d). According to the values of $\mathrm{K}_{\mathrm{m}}, \mathrm{Mn}: \mathrm{N}-\mathrm{CDs}$ show a higher affinity to $\mathrm{H}_{2} \mathrm{O}_{2}$ compared with N-CDs. This may be because the increased amount of hydrophilic functional groups facilitates the interaction between $\mathrm{H}_{2} \mathrm{O}_{2}$ and $\mathrm{Mn}: \mathrm{N}-\mathrm{CDs}$, resulting in superior enzymatic activity compared with that of N-CDs. In addition, no noticeable toxicity is observed in Mn:N-CDs up to $0.5 \mathrm{mg} \cdot \mathrm{mL}^{-1}$ when they are co-cultured with lung cancer cells (A549) and kidney cells (HEK293) for $24 \mathrm{~h}$ (Supplementary Materials Figure S5). Hence, Mn:N-CDs with high enzymatic activity and biocompatibility are suitable as a colorimetric probe in various biological applications.

a

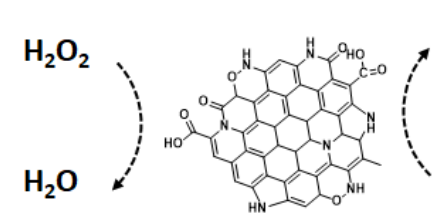

C

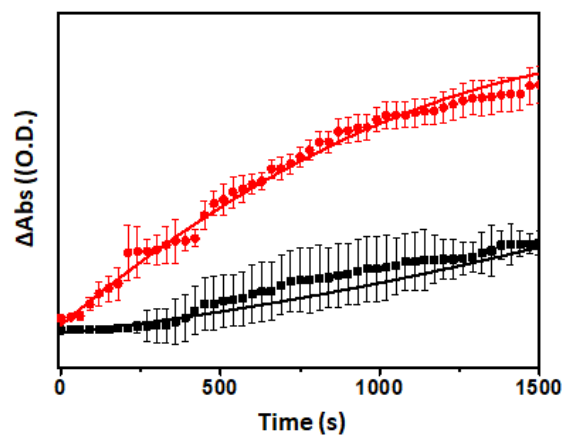

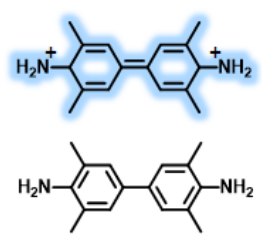

b
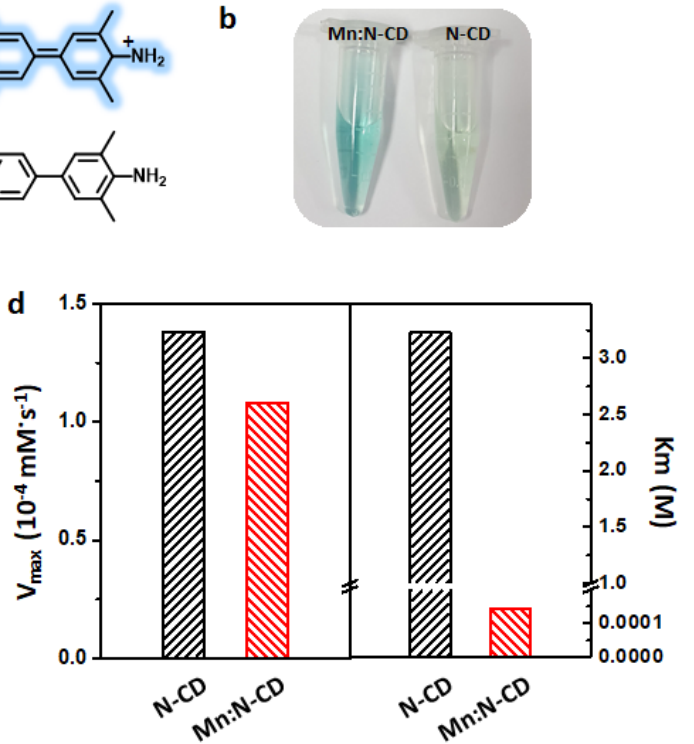

Figure 3. (a) Schematic of the peroxidase mimetic activity of Mn:N-CDs and (b) images of 3,3',5,5'tetramethylbenzidine (TMB) $/ \mathrm{H}_{2} \mathrm{O}_{2}$ solutions with $\mathrm{Mn}$ : N-CDs or N-doped carbon dots (N-CDs). (c) Kinetic curves of Mn:N-CDs and N-CDs for monitoring the catalytic oxidation of TMB (10 mM phosphate buffer, $\mathrm{pH}=2$ ) with $100 \mathrm{mM} \mathrm{H}_{2} \mathrm{O}_{2}$ in the presence of the $\mathrm{Mn}: \mathrm{N}-\mathrm{CD}$ or N-CDs. (d) Comparison of the $V_{\max }$ and $K_{\mathrm{m}}$ values of Mn:N-CDs and N-CDs; these were calculated from the Lineweaver-Burk plot $(n=3)$.

As the color change originating from the enzyme-like activity of Mn:N-CDs can be easily observed with the naked eye, it is advantageous to apply them in colorimetric sensor systems. In recent years, numerous research groups have examined the metabolism of the human microbiome and its relevance to diseases [41-44], and information about the 
composition of the microbiome or its metabolites can be quite helpful for understanding their relevance [45]. GABA is not only a representative metabolite released in the metabolic process of the microbiome but also an inhibitory neurotransmitter that acts on the central nervous system of mammals [45-47]. Therefore, it can be an indicator of the association between intestinal microbiota and brain-related diseases. Because GABA contains a carboxyl group and an amine in one molecule, the net charge varies with the $\mathrm{pH}$. At $\mathrm{pH}$ 2, where the peroxidase-like property of Mn:N-CDs is maximized (Supplementary Materials Figure S6), GABA can lead to the aggregation of anionic Mn:N-CDs through electrostatic attractions owing to the positive charge on GABA (Figure 4a). The aggregation of Mn:N-CDs can change their enzymatic activity owing to variations in their surface area or the pathway of electron migration. At $\mathrm{pH} 2$, the $\zeta$ potentials of $\mathrm{Mn}: \mathrm{N}-\mathrm{CDs}$ and GABA are measured to be -1.56 and $1.74 \mathrm{eV}$, respectively, whereas the net charge of the mixture of Mn:N-CDs and GABA is evaluated as neutral $(-0.17 \mathrm{eV})$. Unlike Mn:N-CDs only, when the mixture of GABA and Mn:N-CDs is added to the reaction solution containing TMB and $\mathrm{H}_{2} \mathrm{O}_{2}$, there is no recognizable change in the color of the solution (Figure $4 \mathrm{~b}$ ). When the absorbance (at $652 \mathrm{~nm}$ ) of the reaction solution is monitored, the change in absorbance change is significantly suppressed by the addition of both GABA and Mn:N-CDs, in contrast with the reaction solution with Mn:N-CDs only (Figure 4c). On the other hand, the addition of other small molecules such citric acid, L-glutamic acid, and L-ascorbic acid does not perturb the enzymatic activity of Mn:N-CDs (Supplementary Materials Figure S7). GABA in artificial urine (BZ103, Biochemazone ${ }^{\mathrm{TM}}$, Edmonton, Canada) is also successfully detected using Mn:N-CDs (Supplementary Materials Figure S8). When the absorbance change of the solution is examined by adding GABA at different concentrations $(0-400 \mathrm{nM})$, the absorbance decreases proportionally with the increasing GABA concentration. In particular, the absorbance change shows a linear correlation in the GABA concentration from 50 to $300 \mathrm{nM}$ (Figure $4 \mathrm{~d}$ and Supplementary Materials Figure S9). The limits of detection and quantitation are calculated as $59.191 \mathrm{nM}$ and $179.366 \mathrm{nM}$, respectively (Supplementary Materials Figure S10).Considering that the ranges of GABA concentrations in the blood of normal people and Alzheimer patients are 100-200 nM [48,49], Mn:N-CD-based colorimetric sensor systems can be successfully applied for the indication of disease occurrence.

a
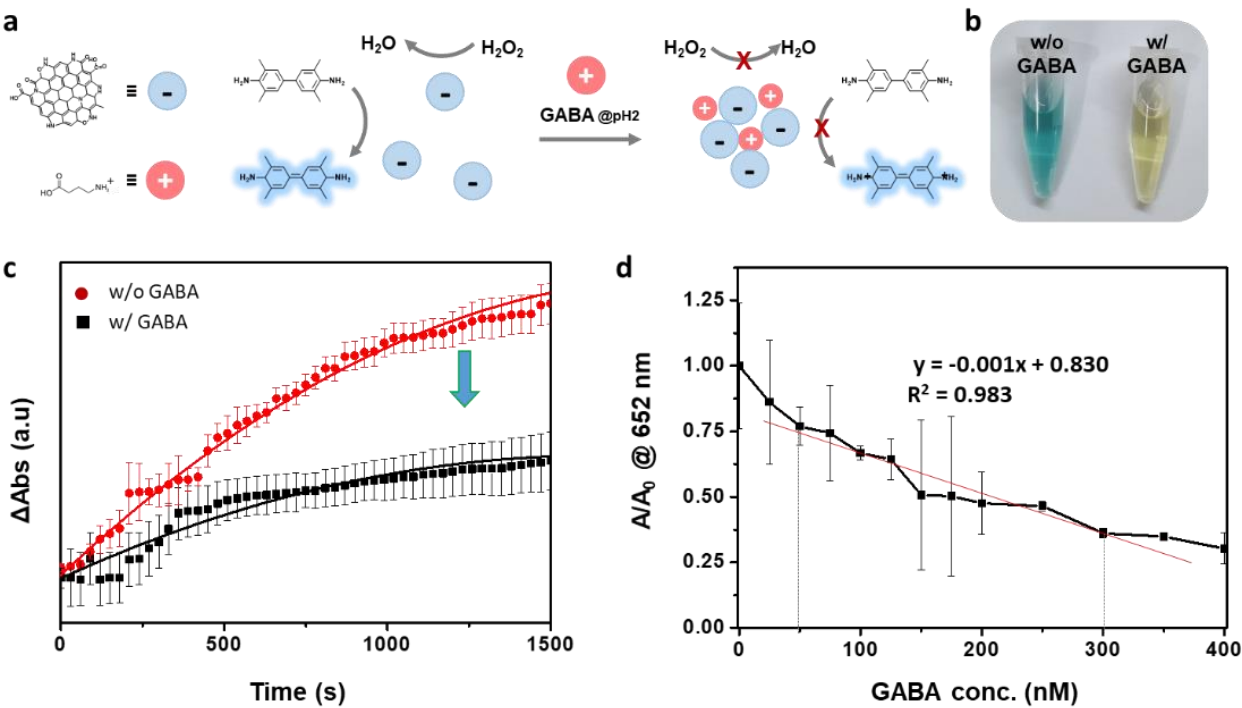

Figure 4. (a) Schematic of $\gamma$-aminobutyric acid (GABA) detection using Mn:N-CDs. (b) Images of $\mathrm{TMB} / \mathrm{H}_{2} \mathrm{O}_{2} / \mathrm{Mn}: \mathrm{N}-\mathrm{CD}$ s solutions with or without GABA. (c) Kinetic curves of Mn:N-CDs with and without GABA for monitoring the catalytic oxidation of TMB $(0.15 \mathrm{M}$ citric acid buffer, $\mathrm{pH}=2)$ with $100 \mathrm{mM} \mathrm{H}_{2} \mathrm{O}_{2}$. (d) Variation in absorption (at $652 \mathrm{~nm}$ ) of the mixed solution containing Mn:N-CDs, GABA, TMB, and $\mathrm{H}_{2} \mathrm{O}_{2}$ as a function of the concentration of GABA. 


\section{Conclusions}

In this study, the nanozyme effect was remarkably increased using Mn(acetate) 2 . Although the exact role of $\mathrm{Mn}$ ions in the formation of Mn:N-CDs has not been explored fully, the addition of $\mathrm{Mn}$ (acetate) $)_{2}$ to the reaction solution seems to generate more functional groups at the edge of carbogenic domains in Mn:N-CDs than in N-CDs, resulting in improved peroxidase-like properties. Mn:N-CDs with strong enzymatic effects can be applied as a colorimetric sensor probe for the detection of GABA. Specifically, the simple addition of GABA significantly suppressed the enzymatic effect of Mn:N-CDs, which was observed using the variation in the intensity of the blue color of the solution. Therefore, Mn:N-CDs are promising candidates as sensing probes that can convert a biological signal to an easily recognizable color, and a Mn: N-CD-based detection system can be applied as a monitoring system in everyday life for the early diagnosis or maintenance of diseases. In addition, through combining with target-specific molecules, Mn:N-CDs can be further applied as sensitive and selective colorimetric sensor probes for the detection of various disease.

Supplementary Materials: The following are available online at https://www.mdpi.com/article/10 .3390 / nano11113046/s1. Figure S1: XRD spectrum of Mn:N-CDs, Figure S2: Comparison of IR spectra of N-CDs and as-synthesized Mn:N-CDs, Table S1: Amount of Mn ions in Mn:N-CDs, Figure S3: Ratios of each component and chemical bonds in N-CDs and Mn:N-CDs, Figure S4: LineweaverBurk plot for the kinetic analysis of N-CDs and Mn:N-CDs, Figure S5: Viability test of N-CDs and $\mathrm{Mn}: \mathrm{N}-\mathrm{CD}$, Figure S6: The image of reaction solution containing TMB, $\mathrm{H}_{2} \mathrm{O}_{2}$, and $\mathrm{Mn}: \mathrm{N}-\mathrm{CDs}$ under different $\mathrm{pH}$, Figure S7: Image of reaction solutions that were mixed with citric acid, L-aspartic acid, and L-glutamic acid, respectively, Figure S8: Image of reaction solutions containing TMB, $\mathrm{H}_{2} \mathrm{O}_{2}$, and $\mathrm{Mn}: \mathrm{N}-\mathrm{CDs}$, that are mixed with GABA containing buffer or artificial urine, individually, Figure S9: Variation in absorption (at $652 \mathrm{~nm}$ ) of the mixed solution containing Mn:N-CDs, GABA, TMB, and $\mathrm{H}_{2} \mathrm{O}_{2}$ as a function of the concentration of GABA, Figure S10: Calculation of limit of detection (LOD) and quantitation (LOQ).

Author Contributions: Conceptualization, methodology, J.-s.C.; validation, A.L., W.K. and J.-s.C.; formal analysis, A.L. and W.K.; investigation, A.L. and W.K..; resources, J.-s.C.; data curation, A.L., W.K. and J.-s.C.; writing-original draft preparation, J.-s.C.; writing-review and editing J.-s.C.; visualization, J.-s.C.; supervision, J.-s.C.; project administration, J.-s.C.; funding acquisition, J.-s.C. All authors have read and agreed to the published version of the manuscript.

Funding: This work is supported by the National Research Foundation of Korea (NRF) grant funded by the Korea government (MSIT) (2020R1C1C1011863 and 2020R1A5A8017671).

Institutional Review Board Statement: Ethical review and approval were waived for this study, because no experiment was involved with humans or animals.

Informed Consent Statement: Not applicable.

Conflicts of Interest: The authors declare no conflict of interest.

\section{References}

1. Hamid, M.; Khalil-ur-Rehman. Potential applications of peroxidases. Food Chem. 2009, 115, 1177-1186. [CrossRef]

2. Regalado, C.; García-Almendárez, B.E.; Duarte-Vázquez, M.A. Biotechnological applications of peroxidases. Phytochem. Rev. 2004, 3, 243-256. [CrossRef]

3. Voller, A.; Bartlett, A.; Bidwell, D.E. Enzyme immunoassays with special reference to ELISA techniques. J. Clin. Pathol. 1978, 31, 507-520. [CrossRef]

4. Taylor, S.L.; Nordlee, J.A.; Niemann, L.M.; Lambrecht, D.M. Allergen immunoassays—Considerations for use of naturally incurred standards. Anal. Bioanal. Chem. 2009, 395, 83-92. [CrossRef] [PubMed]

5. Watanabe, E.; Miyake, S.; Yogo, Y. Review of enzyme-linked immunosorbent assays (ELISAs) for Analyses of neonicotinoid insecticides in agro-environments. J. Agric. Food Chem. 2013, 61, 12459-12472. [CrossRef] [PubMed]

6. Shin, J.H.; Lee, M.J.; Choi, J.H.; Song, J.A.; Kim, T.H.; Oh, B.K. Electrochemical $\mathrm{H}_{2} \mathrm{O}_{2}$ Biosensor based on horseradish peroxidase encapsulated protein nanoparticles with reduced graphene oxide-modified gold electrode. Nano Converg. 2020, 7, 39. [CrossRef] [PubMed]

7. Sun, H.; Liu, Z.; Wu, C.; Xu, P.; Wang, X. Amperometric Inhibitive biosensor based on horseradish peroxidase-nanoporous gold for sulfide determination. Sci. Rep. 2016, 6, 30905. [CrossRef] [PubMed] 
8. Pumera, M.; Sánchez, S.; Ichinose, I.; Tang, J. Electrochemical nanobiosensors. Sens. Actuators B 2007, 123, 1195-1205. [CrossRef]

9. Grieshaber, D.; MacKenzie, R.; Vörös, J.; Reimhult, E. Electrochemical biosensors-Sensor principles and architectures. Sensors 2008, 8, 1400-1458. [CrossRef]

10. Zhang, Y.; Jin, Y.; Cui, H.; Yan, X.; Fan, K. Nanozyme-based catalytic theranostics. RSC Adv. 2020, 10, 10-20. [CrossRef]

11. Huang, Y.; Ren, J.; Qu, X. Nanozymes: Classification, catalytic mechanisms, activity regulation, and applications. Chem. Rev. 2019, 119, 4357-4412. [CrossRef]

12. Jiang, D.; Ni, D.; Rosenkrans, Z.T.; Huang, P.; Yan, X.; Cai, W. Nanozyme: New horizons for responsive biomedical applications. Chem. Soc. Rev. 2019, 48, 3683-3704. [CrossRef] [PubMed]

13. Wang, Q.; Wei, H.; Zhang, Z.; Wang, E.; Dong, S. Nanozyme: An emerging alternative to natural enzyme for biosensing and immunoassay. TrAC Trends Anal. Chem. 2018, 105, 218-224. [CrossRef]

14. Wei, H.; Wang, E. Nanomaterials with Enzyme-Like Characteristics (Nanozymes): Next-Generation Artificial Enzymes. Chem. Soc. Rev. 2013, 42, 6060-6093. [CrossRef]

15. Azzouz, A.; Goud, K.Y.; Raza, N.; Ballesteros, E.; Lee, S.-E.; Hong, J.; Deep, A.; Kim, K.-H. Nanomaterial-based electrochemical sensors for the detection of neurochemicals in biological matrices. TrAC Trends Anal. Chem. 2019, 110, 15-34. [CrossRef]

16. Thangudu, S.; Lee, M.T.; Rtimi, S. Tandem synthesis of high yield MoS2 nanosheets and enzyme peroxidase mimicking properties. Catalysts 2020, 10, 1009. [CrossRef]

17. Thangudu, S.; Su, C.H. Peroxidase mimetic nanozymes in cancer phototherapy: Progress and perspectives. Biomolecules 2021, 11, 1015. [CrossRef]

18. Choi, Y.; Choi, Y.; Kwon, O.H.; Kim, B.S. Carbon Dots: Bottom-up syntheses, properties, and light-harvesting applications. Chem. Asian J. 2018, 13, 586-598. [CrossRef] [PubMed]

19. Das, R.; Bandyopadhyay, R.; Pramanik, P. Carbon quantum dots from natural resource: A review. Mater. Today Chem. 2018, 8, 96-109. [CrossRef]

20. Jesús Lázaro, M.J.; Ascaso, S.; Pérez-Rodríguez, S.; Calderón, J.C.; Gálvez, M.E.; Jesús Nieto, M.; Moliner, R.; Boyano, A.; Sebastián, D.; Alegre, C.; et al. Carbon-based catalysts: Synthesis and applications. C. R. Chim. 2015, 18, 1229-1241. [CrossRef]

21. Dehvari, K.; Chiu, S.H.; Lin, J.S.; Girma, W.M.; Ling, Y.C.; Chang, J.Y. Heteroatom doped carbon dots with nanoenzyme like properties as theranostic platforms for free radical scavenging, imaging, and chemotherapy. Acta Biomater. 2020, 114, 343-357. [CrossRef]

22. Lee, A.; Yun, S.; Kang, E.S.; Kim, J.W.; Park, J.H.; Choi, J. Effect of heteroatoms on the optical properties and enzymatic activity of N-doped carbon dots. RSC Adv. 2021, 11, 18776-18782. [CrossRef]

23. Tripathi, K.M.; Ahn, H.T.; Chung, M.; Le, X.A.; Saini, D.; Bhati, A.; Sonkar, S.K.; Kim, M.I.; Kim, T. N, S, and P-Co-doped carbon quantum dots: Intrinsic peroxidase activity in a wide PH range and its antibacterial applications. ACS Biomater. Sci. Eng. 2020, 6, 5527-5537. [CrossRef]

24. Honarasa, F.; Peyravi, F.; Amirian, H. C-Dots $/ \mathrm{Mn}_{3} \mathrm{O}_{4}$ Nanocomposite as an oxidase nanozyme for colorimetric determination of ferrous ion. J. Iran. Chem. Soc. 2020, 17, 507-512. [CrossRef]

25. Xi, J.; Xie, C.; Zhang, Y.; Wang, L.; Xiao, J.; Duan, X.; Ren, J.; Xiao, F.; Wang, S. Pd nanoparticles decorated N-doped graphene quantum Dots@N-doped carbon hollow nanospheres with high electrochemical sensing performance in cancer detection. ACS Appl. Mater. Interfaces 2016, 8, 22563-22573. [CrossRef]

26. Li, C.; Qin, Z.; Wang, M.; Liu, W.; Jiang, H.; Wang, X. Manganese oxide doped carbon dots for temperature-responsive biosensing and target bioimaging. Anal. Chim. Acta 2020, 1104, 125-131. [CrossRef]

27. Luo, D.L.; Chen, B.; Li, X.; Liu, Z.; Liu, X.; Liu, X.; Shi, C.; Zhao, X.S. Three-dimensional nitrogen-doped porous carbon anchored $\mathrm{CeO}_{2}$ quantum dots as an efficient catalyst for formaldehyde oxidation. J. Mater. Chem. A 2018, 6, 7897-7902. [CrossRef]

28. Zhao, J.; Wang, H.; Geng, H.; Yang, Q.; Tong, Y.; Au He, W. Au/N-doped carbon dot nanozymes as light-controlled anti- and pro-oxidants. ACS Appl. Nano Mater. 2021, 4, 7253-7263. [CrossRef]

29. Cheng, J.; Wang, C.-F.; Zhang, Y.; Yang, S.; Chen, S. Zinc ions doped carbon dots with strongly yellow photoluminescence. RSC Adv. 2016, 6, 37189-37194. [CrossRef]

30. Zhuo, S.; Fang, J.; Li, M.; Wang, J.; Zhu, C.; Du, J. Manganese(II)-doped carbon dots as effective oxidase mimics for sensitive colorimetric determination of ascorbic acid. Mikrochim. Acta. 2019, 186, 745. [CrossRef] [PubMed]

31. Li, L.; Deng, Y.; Ai, J.; Li, L.; Liao, G.; Xu, S.; Wang, D.; Zhang, W. Fe/Mn loaded sludge-based carbon materials catalyzed oxidation for antibiotic degradation: Persulfate vs. $\mathrm{H}_{2} \mathrm{O}_{2}$ as oxidant. Sep. Purif. Technol. 2021, 263, 118409. [CrossRef]

32. Zhang, J.; Wu, S.; Lu, X.; Wu, P.; Liu, J. Manganese as a catalytic mediator for photo-oxidation and breaking the PH limitation of nanozymes. Nano Lett. 2019, 19, 3214-3220. [CrossRef] [PubMed]

33. Miao, X.; Qu, D.; Yang, D.; Nie, B.; Zhao, Y.; Fan, H.; Sun, Z. Synthesis of carbon dots with multiple color emission by controlled graphitization and surface functionalization. Adv. Mater. 2018, 30, 1704740. [CrossRef] [PubMed]

34. Pal, A.; Sk, M.P.; Chattopadhyay, A. Recent advances in crystalline carbon dots for superior application potential. Mater. Adv. 2020, 1, 525-553. [CrossRef]

35. Bajpai, S.K.; D'Souza, A.; Suhail, B. Blue light-emitting carbon dots (CDs) from a milk protein and their interaction with spinacia oleracea leaf cells. Int. Nano Lett. 2019, 9, 203-212. [CrossRef]

36. Abdullah Issa, M.; Abidin, Z.Z.; Sobri, S.; Rashid, S.; Adzir Mahdi, M.; Azowa Ibrahim, N.; Pudza, M.Y. Facile synthesis of nitrogen-doped carbon dots from lignocellulosic waste. Nanomaterials 2019, 9, 1500. [CrossRef] [PubMed] 
37. Kross, R.D.; Fassel, V.A. The infrared spectra of aromatic compounds. IV. The nitro valence vibrations in p-disubstituted nitrobenzenes ${ }^{1}$. J. Am. Chem. Soc. 1956, 78, 4225-4229. [CrossRef]

38. Yancheva, D.Y. Characterization of the Structure, electronic conjugation and vibrational spectra of the radical anions of $\mathrm{p}-$ and m-dinitrobenzene: A quantum chemical study. Bulg. Chem. Commun. 2013, 45, 24-31.

39. Van Veen, A.; Verkade, P.E.; Wepster, B.M. Steric effects in the infra-red spectrum of aromatic nitro compounds. Recl. Trav. Chim. Pays-Bas 2010, 76, 801-809. [CrossRef]

40. Bhattacharyya, S.; Ehrat, F.; Urban, P.; Teves, R.; Wyrwich, R.; Döblinger, M.; Feldmann, J.; Urban, A.S.; Stolarczyk, J.K. Effect of nitrogen atom positioning on the trade-off between emissive and photocatalytic properties of carbon dots. Nat. Commun. 2017, 8, 1401. [CrossRef]

41. Martin, C.R.; Osadchiy, V.; Kalani, A.; Mayer, E.A. The brain-gut-microbiome axis. Cell. Mol. Gastroenterol. Hepatol. 2018, 6, 133-148. [CrossRef] [PubMed]

42. Zhu, S.; Jiang, Y.; Xu, K.; Cui, M.; Ye, W.; Zhao, G.; Jin, L.; Chen, X. The progress of gut microbiome research related to brain disorders. J. Neuroinflammat. 2020, 17, 25. [CrossRef] [PubMed]

43. Liu, P.; Peng, G.; Zhang, N.; Wang, B.; Luo, B. Crosstalk between the gut microbiota and the brain: An update on neuroimaging findings. Front. Neurol. 2019, 10, 883. [CrossRef]

44. Ezzeldin, S.; El-Wazir, A.; Enany, S.; Muhammad, A.; Johar, D.; Osama, A.; Ahmed, E.; Shikshaky, H.; Magdeldin, S. Current understanding of human metaproteome association and modulation. J. Proteome Res. 2019, 18, 3539-3554. [CrossRef] [PubMed]

45. Bhandage, A.K.; Cunningham, J.L.; Jin, Z.; Shen, Q.; Bongiovanni, S.; Korol, S.V.; Syk, M.; Kamali-Moghaddam, M.; Ekselius, L.; Birnir, B. Depression, GABA, and age correlate with plasma levels of inflammatory markers. Int. J. Mol. Sci. 2019, $20,6172$. [CrossRef]

46. O'Connor, K.; Waters, P.; Komorowski, L.; Zekeridou, A.; Guo, C.Y.; Mgbachi, V.C.; Probst, C.; Mindorf, S.; Teegen, B.; Gelfand, J.M.; et al. $\mathrm{GABA}_{\mathrm{A}}$ receptor autoimmunity: A multicenter experience. Neurol. Neuroimmunol. Neuroinflamm. 2019, 6, e552. [CrossRef]

47. Xie, J.; Song, Y.; Dai, Y.; Li, Z.; Gao, F.; Li, X.; Xiao, G.; Zhang, Y.; Wang, H.; Lu, Z.; et al. Nanoliposome-encapsulated caged-GABA for modulating neural electrophysiological activity with simultaneous detection by microelectrode arrays. Nano Res. 2020, 13, 1756-1763. [CrossRef]

48. Ebert, M.H.; Schmidt, D.E.; Thompson, T.; Butler, M.G. Elevated plasma gamma-aminobutyric acid (GABA) levels in individuals with either prader-willi syndrome or angelman syndrome. J. Neuropsychiatry Clin. Neurosci. 1997, 9, 75-80. [CrossRef]

49. Seidl, R.; Cairns, N.; Singewald, N.; Kaehler, S.T.; Lubec, G. Differences between GABA levels in Alzheimer's disease and down syndrome with alzheimer-like neuropathology. Naunyn Schmiedebergs Arch. Pharmacol. 2001, 363, 139-145. [CrossRef] 